\begin{tabular}{|c|c|c|}
\hline $\begin{array}{l}\text { An International Biannual Open Access } \\
\text { Peer-Reviewed/Refereed Journal } \\
\text { JOURNAL OF GLOBAL RESOURCES } \\
\text { Published by : ISDESR, Jaipur, India }\end{array}$ & $\begin{array}{l}\text { a } \\
\text { www.isdest.org }\end{array}$ & $\begin{array}{r}\text { ISSN: 2395-3160 (Print) } \\
\text { ISSN: } 2455-2445 \text { (Online) } \\
\text { January 2022, Volume 08 (01) } \\
\text { DOI Prefix: } 10.46587 / J G R\end{array}$ \\
\hline
\end{tabular}

10

\title{
A STUDY OF CORROSION INHIBITON EFFECT OF THIOSEMICARBAZIDE BASED SCHIFF BASE ON ALUMINIUM METAL IN ACIDIC MEDIUM
}

\author{
Sanjay Kumar ${ }^{1}$, Amarchand Kumawat ${ }^{2}$ and V. K. Swami ${ }^{3}$ \\ ${ }^{1}$ Research Laboratory, Govt. Lohia P. G. College, Churu (Raj.) India \\ 2,3S. B. D. Govt. P. G.College, Sardarshahar, Churu, India \\ Corresponding Author: sanjaysnkp@gmail.com
}

How to cite this paper:

Sanjay Kumar; Kumawat, Amarchand and Swami, V. K. (2022) A Study of Corrosion Inhibiton Effect of Thiosemicarbazide based Schiff base on Aluminium metal in Acidic Medium, Journal of Global Resources, Vol. 08 (01)

DOI:

10.46587/JGR.2022.v08i01.010

Received: 15 Oct. 2021

Reviewed: 30 Oct. 2021

Revised: 09 Dec. 2021

Final Accepted: 11 Dec. 2021

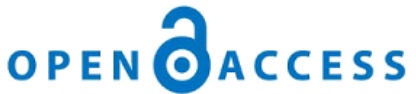

Freely available Online www.isdesr.org

\begin{abstract}
Corrosion is the destruction of metal surface by the reaction with its environment (humidity, gases, acid, alkaline etc.). In this process metal convert in to the more stable form such as sulphide oxide etc. Corrosion of materials and structures is a hindrance to the development of society as it causes significant loss to the economy, leads to pollution, and leads to serious disasters, hence its prevention and control is of great benefit for the humanity. Addition of corrosion inhibitors is one of the practical and easy methods to protect metals and alloys against attack of corrosion in many industrial environments. In this chapter thiosemicarbazide based Schiff base 2-[(3,4-dihydroxy-5-nitrophenyl)methylidene]hydrazine1-carbothioamide (DHNPMHC) was synthesized and characterized using elemental analysis, FT-IR and UV-Vis methods. The inhibition efficiency of Schiff base DHNPMHC against aluminium corrosion in $0.5 \mathrm{M} \mathrm{HCl}$ was examined using mass loss measurement and scanning electron microscopy (SEM). Results showed that DHNPMHC is an effective inhibitor for aluminium corrosion in $0.5 \mathrm{M} \mathrm{HCl}$ solution. The inhibition efficiency also increased with concentration of inhibitor increased. Maximum percentage inhibition efficiency $92.6 \%$ (at 4-hour immersion time) is shown at highest concentration of inhibitor $5 \%\left(5 \times 10^{-5} \mathrm{M}\right)$. Adsorption of the inhibitor on the aluminium surface followed Langmuir adsorption isotherm. SEM study of aluminium surface in presence of inhibitor and in absence of inhibitor also supports the inhibition of corrosion in acidic medium. All results show that the Schiff base of thiosemicarbazide (DHNPMHC) is excellent corrosion inhibitor for aluminium in $0.5 \mathrm{M} \mathrm{HCl}$.
\end{abstract}

Key words: DHNPMHC, Corrosion, Inhibition Efficiency, Aluminium, Mass Loss Measurement, SEM. 


\section{Introduction}

Nature providing us valuable resources likes air, water, materials etc. on the earth. In nature different phenomenon happened continuously likes rain, combustion, volcanic eruption, corrosion of materials etc. Our material resources such as copper, iron, aluminium, chromium, manganese, etc., are vanishing day by day. If it continues like this, soon we will be facing acute shortage of materials. The upcoming metal crisis is harsh reality rather than just a possibility. In metallurgy pure metal like $\mathrm{Fe}, \mathrm{Cu}, \mathrm{Al}$ etc. extracted from their ores by different chemical and physical methods. In corrosion process metal reacts with its environment (humidity, gases, acid, alkaline etc.) and convert into the more stable form such as sulphide oxide etc. Due to corrosion mechanical properties of metals become changed, hence causes materials failure in nature [1-5]. Corrosion of materials and structures is a hindrance to the development of society as it causes significant loss to the economy, leads to pollution, and leads to serious disasters, hence its prevention and control is of great benefit for the humanity. The economic cost of corrosion all over the world is enormous and goes into billions of dollars. According to a report of National Metallurgical Laboratory (NML), Jamshedpur, the figure of Rs 1.07 lakh crore given by National Association of Corrosion Engineers (NACE) recently excluded corrosion losses being incurred by the country's small \& medium enterprises (SMEs) engaged both in manufacturing and utility services sectors.

According to NACE international impact report 2013 on corrosion of metals "The global cost of corrosion is estimated to be US $\$ 2.5$ trillion, which is equivalent to $3.4 \%$ of the global gross domestic product (GDP)" [6]. Corrosion process in industries and engineering structures is the main dangerous problem of materials failure and loss of lives. In last decades, there are several cases of engineering structure failure and aircraft accidents happened where hundreds live lost. In these accidents corrosion of materials is directly or indirectly responsible [7-9]. Aluminum is one of the world's most commonly used metal. The aluminium is a soft, nonmagnetic, nontoxic, ductile, low density, highly electrical conductive and highly corrosion resistant element. Due to these properties it has wide range of applications such as: in structural materials (in aircraft, ships, cars, and heat exchangers), in buildings, in packaging (in cans, foil, frame etc.), for cooking utensils, to make electrical power cables etc. Aluminium forms a diversity of alloys which have a wide range of properties and applications. It is also easy to form and recycle [1011]. $\mathrm{HCl}$ is commonly used for acid cleaning, acid de-scaling, chemical and electrochemical etching in many industries where in aluminium and its alloys are used [12-14]. Due to use of $\mathrm{HCl}$ aluminium easily gets corroded. Corrosion of metals is a continuous process and difficult to eliminate completely. Addition of corrosion inhibitors is one of the practical and easy methods to protect metals and alloys against attack of corrosion in many industrial environments. Different corrosion protection is in practice present time. The use of organic corrosion inhibitors is also practical and easiest method for protection of corrosion of metals in acidic medium [15-16]. Compounds containing hetero atoms such as sulfur, nitrogen, phosphorus, or oxygen are often found to be good corrosion inhibitors for metal corrosion. The corrosion inhibition efficiency of organic inhibitor is depending on the structural properties of the compound like functional groups (methoxy, amino, hydroxy etc.), electron density at the donor atom and the presence of aromaticity the molecule [17-18]. Synthetic inhibitors that are in practice have created environmental problems due to its toxicity properties. They also changed the properties of metals. Thus it is important and necessary to develop low cost and ecofriendly organic corrosion inhibitors [19-20].

In last decades, the efficiency of Schiff bases as organic corrosion inhibitors for metals corrosion in acidic medium has been widely reported [21-26]. The Schiff base of thiosemicarbazide (DHNPMHC) is nontoxic and soluble in aqueous media in presence of 
Dimethyl sulphoxide (DMSO). It is relatively cheap and easy to produce with high yield. These properties would justify the use of Schiff base of thiosemicarbazide as corrosion inhibitor towards metal corrosion in acidic medium. The object of this study to examined anticorrosive properties of thiosemicarbazide based Schiff base 2-[(3,4-dihydroxy-5-nitrophenyl)methylidene]hydrazine-1carbothio amide (DHNPMHC) on aluminium corrosion in $0.5 \mathrm{M} \mathrm{HCl}$.

\section{Synthesis and characterization of 2-[(3,4-dihydroxy-5-nitrophenyl) methylidene] hydrazine-1-carbothio amide (DHNPMHC):}

\section{Synthesis of (DHNPMHC):}

The entire chemical used to synthesize the organic inhibitor DHNPMHC were analytical grade. The organic inhibitor DHNPMHC has been synthesized and characterized on the basis of previous reported research studies [27-31]

The Schiff base 2-[(3,4-dihydroxy-5-nitrophenyl)methylidene]hydrazine-1-carbothio amide (DHNPMHC) was synthesized from the condensation of 3,4-dihydroxcy-5-nitrobenzaldehyde $(2 \mathrm{gm})$ and thiosemicarbazide $(2 \mathrm{gm})$ in ethanol $(20 \mathrm{ml})$ in presence of glacial acetic acid $(2 \mathrm{ml})$. The content was refluxed about $6-7$ hours at $70^{\circ} \mathrm{C}$ in round bottom flask. On cooling the contents the shining yellow colored solid (M.P. $175-180^{\circ} \mathrm{C}$ ) separated out. The yield of (DHNPMHC) is $3.35 \mathrm{gm}$ $(81.25 \%)$. The method of synthesis is summarized in Figure 01.

Figure 01: Reaction Scheme

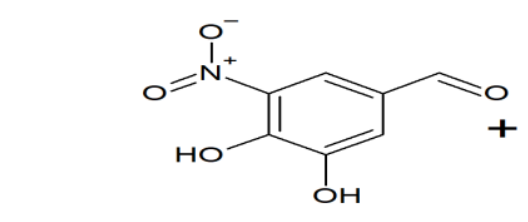

3,4-dihydroxy-5-nitrobenzaldehyde

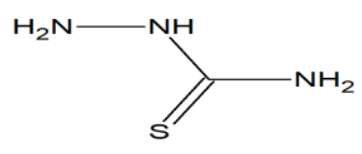

thiosemicarbazide

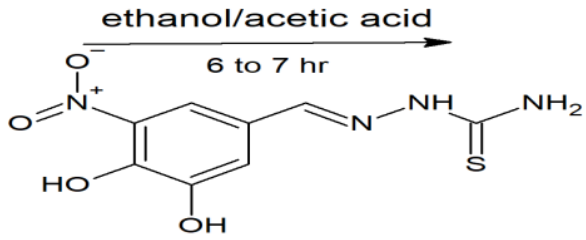

\section{Characterization of DHNPMHC:}

The structure of compound was characterized by elemental analysis, IR and electronic studies. IR studies support the synthesis of DHNPMHC. In the IR spectrum of the compound presence of $\mathrm{U}(\mathrm{C}=\mathrm{N})$ band at $1695-1650 \mathrm{~cm}^{-1}$ confirm the condensation between aldehyde group of 3,4dihydroxcy-5-nitro-benzaldehyde and amino group of thiosemicarbzide. In the UV-Visible spectrum of DHNPMHC $n \rightarrow \pi *$ absorption peak of azomethine group were observed at 352 , $366.5,390,391,416 \mathrm{~nm}$.

\section{Experimental}

\section{Mass Loss Measurement:}

It is a most convenient and easiest method for measuring different corrosion parameters of metal corrosion. In this study mass loss in absence of inhibitor and in presence of inhibitor in corrosive media $(0.5 \mathrm{M} \mathrm{HCl})$ were measured at different time interval (4 hours to 72 hours). For the mass loss study rectangular aluminium specimens of size $3.0 \mathrm{~cm} \times 3.0 \mathrm{~cm} \times 0.1 \mathrm{~cm}$ were used. Test solutions with given concentration of the inhibitor in the acid was prepared by properly diluting the bulk solution of the inhibitor $(.01 \mathrm{~N})$. In this study inhibitor concentrations range was used varied from $1.0 \%$ to $5.0 \%$. The corrosion parameters mass loss, inhibition efficiency, surface coverage and corrosion rate were incorporate in table 01.

The percentage inhibition efficiency $(\eta)$ of metal has been determined by using the given formula:

$$
\eta=\left[\frac{\Delta \mathrm{Mu}-\Delta \mathrm{Mi}}{\Delta \mathrm{Mu}}\right] \times 100
$$


Where,

$\Delta \mathrm{M}_{\mathrm{u}}=$ Mass loss of metal only in presence of corrosive solution

$\Delta \mathrm{M}_{\mathrm{i}}=$ Mass loss of metal in presence of inhibitor

The degree of Surface coverage $(\theta)$ of metal coupon by inhibitor was calculated as:

$$
\theta=\frac{\Delta \mathrm{Mu}-\Delta \mathrm{Mi}}{\Delta \mathrm{Mu}}
$$

The corrosion rate $(\mathrm{CR})$ of corrosion process in millimeter per year can be calculated as:

Where,

$$
\mathrm{CR}(\mathrm{mm} / \mathrm{yr})=\frac{\text { Mass loss } \times 87.6}{d A T} \text {. }
$$

$$
\begin{aligned}
& d=\text { density of aluminium } \\
& A=\text { surface area of metal coupon } \\
& T=\text { immersion time in } \mathrm{HCl}
\end{aligned}
$$

\section{Surface Morphological Studies:}

Scanning electron microscopy (SEM) is an important electron microscopy technique that is used to take visual image of a particle with high quality and spatial resolution. SEM is largely employed to observe the surface phenomenon of the materials. In this chapter Scanning Electron Microscope (TESCAN, MODEL: VEGA3XMU) is used to study the corrosive surface of aluminium in presence of inhibitors and absence of inhibitors. The surface morphology of the aluminium surface after its immersion in the acidic medium in the absence and in the presence of the DHNPMHC (at $5 \%$ concentrations) was carried out by scanning electron microscope (SEM) at $25.0 \mathrm{kv}$ and $10 \mu \mathrm{m}$ resolution.

\section{Adsorption Isotherms:}

The corrosion inhibitors generally adsorb on the metal surface and protect the surface from external corrosive environment. An adsorption isotherm is the mathematical expression, which relates the bulk concentration of adsorbing species to its surface concentration at constant temperature. An adsorption isotherm gives the relationship between the surface coverage of a surface with an adsorbed species and the concentration of the species in solution. Most of the organic inhibitors obey Langmuir adsorption isotherm. According to Langmuir adsorption isotherm the plot between $\log \theta /(1-\theta) v / s \log C$ show linearity.

\section{Result and Discussion}

In this study corrosion inhibition behavior of thiosemicarbazide based Schiff base DHNPMHC towards aluminium corrosion in $0.5 \mathrm{M} \mathrm{HCl}$ has been studied. In this study effects of immersion time and inhibitor concentration on inhibition efficiency were examined. Result of mass loss measurement shows that inhibition efficiency of DHNPMHC decreases with increasing immersion time. Corrosion rate of metal corrosion in $0.5 \mathrm{M} \mathrm{HCl}$ slow down by using inhibitor. It decreases with increasing the concentration of inhibitor. The inhibition efficiency increases with increasing the concentration of inhibitor and maximum percentage Inhibition efficiency $92.6 \%$ shown at $5 \%$ $\left(5 \times 10^{-5} \mathrm{M}\right)$ inhibitor concentration at 4-hour time interval (Figure 02.a). The above statements it is clear that the inhibitor adsorbed on the aluminium surface and forms a protecting layer. The plot $\log (\theta / 1-\theta)$ versus $\log C(\mathrm{~mol} / \mathrm{L})$ shows linearity which indicate the adsorption of Schiff base of thiosemicarbazide on aluminium surface obey Langmuir adsorption pattern (Figure 02.b).

The SEM images of aluminum (fresh aluminium, in $0.5 \mathrm{M} \mathrm{HCl}$ and with inhibitors for a period of 4 hour ) are shown in Figure 04a-c. On comparison of SEM images it is clear that the metal surface was smooth when inhibitor used, whereas the surface is damaged in the case of aluminium immersed in $0.5 \mathrm{M} \mathrm{HCl}$ without inhibitor. 
Table 01: Concentration of inhibitor (COI), mass loss, inhibition efficiency $(\eta)$, surface coverage $(\theta)$ and corrosion rate for aluminium metal in presence of DHNPMHC at different time interval

\begin{tabular}{|c|c|c|c|c|c|c|c|c|c|c|c|c|c|c|c|c|}
\hline \multirow{2}{*}{$\begin{array}{c}\mathrm{C} \\
\mathrm{O} \\
\mathrm{I}(\%)\end{array}$} & \multicolumn{4}{|c|}{4 hours } & \multicolumn{4}{|c|}{24 hours } & \multicolumn{4}{|c|}{48 hours } & \multicolumn{4}{|c|}{72 hours } \\
\hline & $\begin{array}{c}\Delta \mathrm{M} \\
(\mathrm{mg})\end{array}$ & $\begin{array}{c}\eta \\
(\%)\end{array}$ & $\theta$ & $\begin{array}{l}\text { CR } \\
(\mathrm{m} \\
\mathrm{m} / \\
\mathrm{yr} .)\end{array}$ & $\begin{array}{c}\Delta \mathrm{M} \\
(\mathrm{mg})\end{array}$ & $\begin{array}{c}\eta \\
(\%)\end{array}$ & $\theta$ & $\begin{array}{c}\text { CR } \\
(\mathrm{m} \\
\mathrm{m} / \mathrm{y} \\
\mathrm{r})\end{array}$ & $\begin{array}{c}\Delta \mathrm{M} \\
(\mathrm{mg})\end{array}$ & $\begin{array}{c}\eta \\
(\%)\end{array}$ & $\theta$ & $\begin{array}{c}\text { CR } \\
(\mathrm{m} \\
\mathrm{m} / \mathrm{y} \\
\mathrm{r})\end{array}$ & $\begin{array}{c}\Delta \mathrm{M} \\
(\mathrm{mg})\end{array}$ & $\begin{array}{c}\eta \\
(\%)\end{array}$ & $\theta$ & $\begin{array}{c}\text { CR } \\
(\mathrm{m} \\
\mathrm{m} / \mathrm{y} \\
\mathrm{r})\end{array}$ \\
\hline blank & .82 & . & $\ldots$ & 7.3 & 2.0 & $\ldots$ & $\ldots$ & 3.0 & 2.2 & $\ldots$ & $\ldots$ & 1.6 & 2.7 & $\ldots$ & $\ldots$ & 1.3 \\
\hline 1 & .38 & 53.6 & .53 & 3.4 & .98 & 51 & .51 & 1.4 & .92 & 58 & .58 & .69 & 1.2 & 55.55 & .55 & .60 \\
\hline 2 & .26 & 68.2 & .68 & 2.3 & .53 & 73 & .73 & .79 & .64 & 71 & .71 & .48 & 0.8 & 70.37 & .70 & .40 \\
\hline 3 & .12 & 85.3 & .85 & 1.0 & .40 & 80 & .80 & .60 & .35 & 84 & .84 & .26 & .47 & 82.59 & .82 & .23 \\
\hline 5 & .06 & 92.6 & .92 & .54 & .17 & 91 & .91 & .25 & .23 & 89 & .89 & .17 & .29 & 89.25 & .89 & .14 \\
\hline
\end{tabular}

Figure 02: (a) The graph inhibition efficiency v/s concentration of inhibitor (b) Langmuir

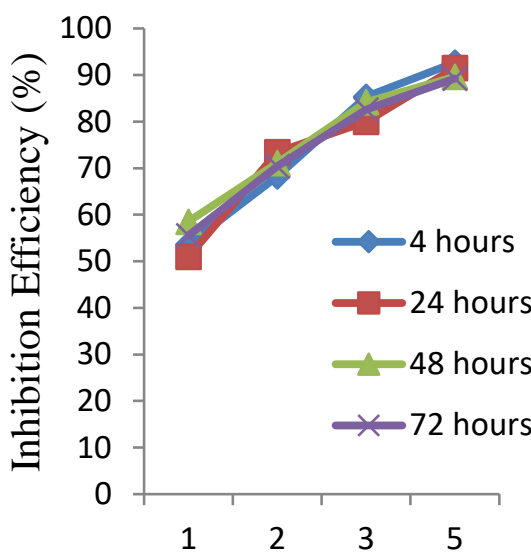

Concentration of inhibitor $(\%)$

(a) adsorption isotherm plot

Figure 03: IR spectrum of DHNPMHC

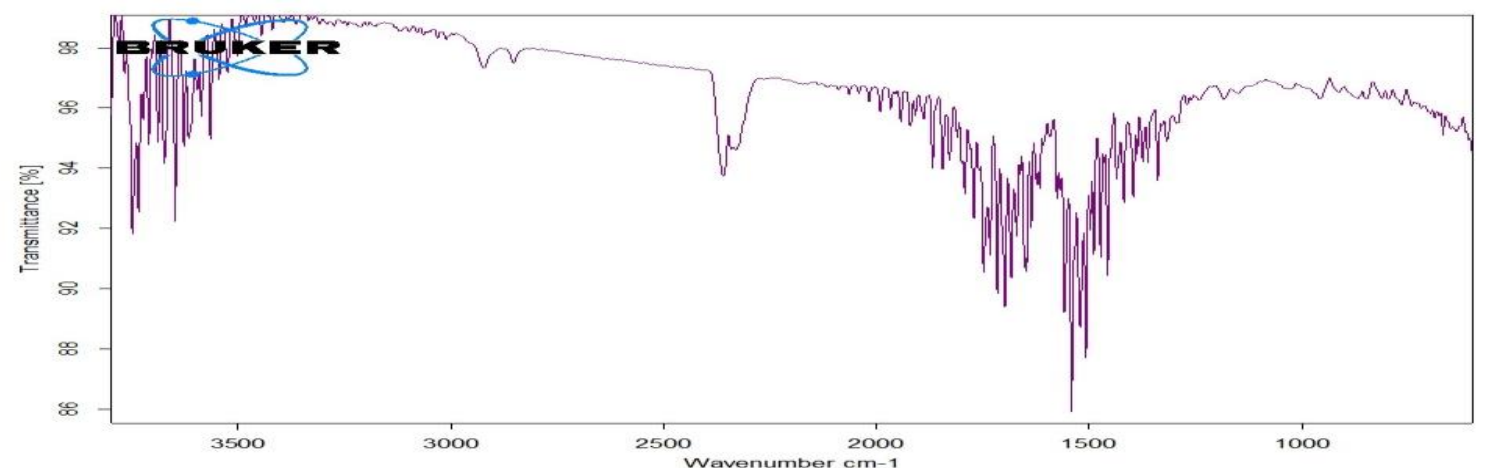

Figure 04: (a) Fresh Aluminum surface. SEM image for $4 \mathrm{hr}$ time duration (b) Al + 0.5M HCl (c) )Al + $0.5 \mathrm{M} \mathrm{HCl}+5 \%$ DHNPMHC

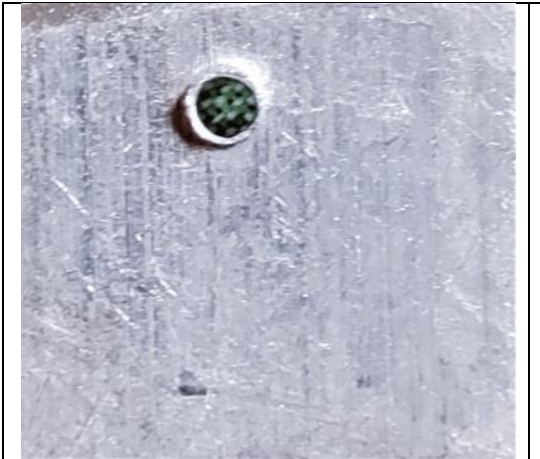

(a)

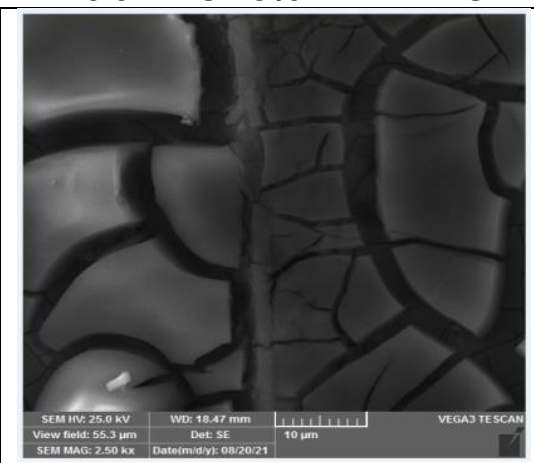

(b)

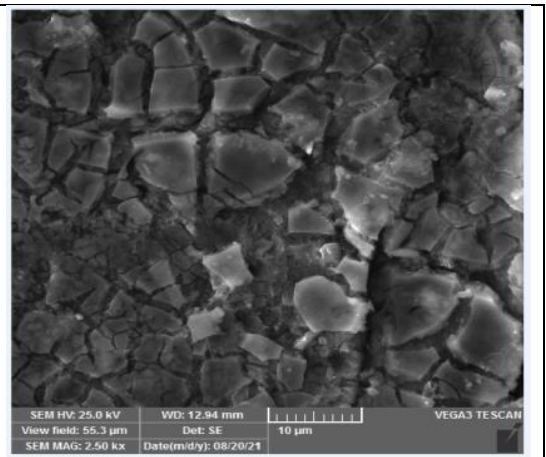

(c)

\section{Conclusion}

The efficiency of synthesized Schiff base of thiosemicarbazide (DHNPMHC) as corrosion inhibition for aluminium in $0.5 \mathrm{M} \mathrm{HCl}$ have been studies. Results obtained from mass loss 
measurements indicate that Schiff base of thiosemicarbazide (DHNPMHC) has good corrosion protection properties towards aluminium metal corrosion in $0.5 \mathrm{HCl}$ solutions. The surface coverage increases with increasing concentration of inhibitor increases. The graph between inhibition efficiency and concentration shows linearity. Adsorption of inhibitor on the surface of aluminium obey Langmuir adsorption isotherm pattern. It means linear plot observed between log $(\theta / 1-\theta)$ versus $\log C(\mathrm{~mol} / \mathrm{L})$. Scanning electron microscopy (SEM) images of aluminium in presence of inhibitor and in absence of inhibitor in acidic medium also supports the inhibition of corrosion. All results of study shows that excellent corrosion protection property of the Schiff base of thiosemicarbazide (DHNPMHC).

Acknowledgement: Special thanks to department of chemistry Dungar College, Bikaner and the Principal, Govt. Lohia (PG) College, Churu provided facility of Research Laboratory. Also a special thanks to Dr. N. K. Soni, NTPC, Noida for providing SEM facility.

\section{References}

1. Karthiga N, Rajendran S, Prabhakar P. and Rathish R. J., (2015). Int. Journal of Nano Corrosion Science \& Engineering, 2(4) 31-49.

2. Tarab S. and Turkustani A. M. A. (2006). Portugaliae Electrochimica Acta, 24, 53-69.

3. Eddy N. O. and Ebenso E. E. (2010). Pigment and Resin Technology, 39, 77-83.

4. Karthik G. and Sundaravadivelu M, (2016). Egyptian Journal of Petroleum, 25,183-191.

5. Hoar T P, Mears D C and Rothwell G P, Corrosion Science, 5(1965) 279-289.

6. Koch G, Varney J, Thompson N, Moghissi O, (2016). Gould M and Payer J, NACE International : IMPACT, Housten TX, 1-6.

7. Popoola L. T, Grema A S, Latinwo G. K, Gutti B. and Balogun A. S., (2013). International Journal of Industrial Chemistry, 2-15.

8. Roberge R, (2020). Corrosion Accidents, Corrosion Doctors

9. https://www.gscsg.com/corrosion-accidents.html. (2020)

10. Davis J R, (1999). Corrosion of Aluminium and Aluminium Alloys, ASM International.

11. Patel A. S, Panchal V. A, Mudaliar G. V. and Shah N. K, (2013). Journal of Saudi Chemical Society, 17(1)53-59.

12. Esquivel J. and Gupta R. K, (2020). Journal of The Electrochemical Society, 167081504.

13. Sukiman N. L, Zhou X, Birbilis N, Hughes A. E, Mol J. M. C., Garcia S. J, Zhou X. and Thompson G. E, (2013). "Aluminium Alloys - New Trends in Fabrication and Application", Intech Open, 47-48.

14. Melchers R. E, (2015). Advances in Materials Science and Engineering, 1-10.

15. Jain P, Patidar B. and Bhawsar J, (2020). Journal of Bio- and Tribo- Corrosion, 6(2) 1-12.

16. Soloman M. M, Umoren S. A. and Qurashi H. A, (2019). Journal of Colloid and interface Science, 551,47-60.

17. Li L, Qu Q, Bai W, Yang F, Chen Y, Zhang S, Ding Z, (2012). Corrosion Science,59, 249-257.

18. Deng S, Li X and Xie X, Corrosion Science, 80(2014) 276-289.

19. Lotto R. T, Lotto C. A. and Popoola A. P. I, (2012). Journal of Materials and Environmental Science, 3 , 885-894.

20. Ladha D. G, Naik U. J. and Shah N. K, (2013). Journal of Materials and Environmental Science, 4, 701-708.

21. Beda R. H. B, Niamien P. M, Bile A. E. B. and Trokourey A, 2017). Advances in Chemistry, 1-10.

22. Muniandy M. T, Rahim A. A, Osman H, Shah A.M, Yahya S. and Raja .P B, (2011). Surface Review and Letters, 18(3) 127-133.

23. Fakrudeen S P, Murthyh A and Raju B, (2012). Journal of the Chilean Chemical Society, 57(4) 13641370.

24. Şafak S, Duran B, Yurt A and Türkoğlu G, Corrosion science, 54, (2012) 251-259.

25. Yurt A. and Aykın Ö, Corrosion Science, 53 (11), (2011) 3725-3732.

26. John S, Ali K M and Joseph A, (2011). Bulletin of Material Science, 34 (6) 1245-1256.

27. Weder N, Alberto R and Koitz R, J. (2016). Phys. Chem. C, 120, 1770-1777.

28. Hammed R. S, (2015). Tenside Surfactants Detergents, 56(3) 209.

29. Al-Labbani H. M. Y, Sejjad F. A. A. and Sahap E. H, (2020). International Journal of Pharmaceutical Research, 12(3) 1304-1309.

30. Naik U. J, Jha P C, Lone M. Y, Shah R. R. and Shah N. K, (2016). Journal of Molecular Structure, 1125, 63-72.

31. Mishra A and Rajyaguru N, (2014). COSMOS: Journal of Engineering \& Technology, 4(2) 1-13. 